\title{
EL DERECHO A SER INFORMADO SOBRE LOS ASUNTOS DE INTERÉS PÚBLICO: DEFENSA DE LOS JUICIOS PARALELOS EN CHILE. PROBLEMAS Y SOLUCIONES
}

\author{
THE RIGHT TO BE INFORMED ON PUBLIC INTEREST ISSUES: \\ DEFENSE OF PARALLEL JUDGMENTS IN CHILE. PROBLEMS AND \\ SOLUTIONS
}

\author{
Carmen Droguett GonZÁlez* \\ Nathalie Walker SiLVA ${ }^{* *}$
}

\begin{abstract}
RESUMEN: El artículo explora los denominados juicios paralelos o mediáticos y su reconocimiento en Chile, con el objetivo de descartar las posturas que refutan su legalidad, fundadas en el menoscabo del derecho a la presunción de inocencia y de las garantías de independencia e imparcialidad del juez o tribunal que conoce de un proceso penal. Como conclusión general, se postula que ello no se verifica en hipótesis donde los derechos y garantías son ejercidos correctamente, especialmente, al interior de un gobierno abierto, que promueva la transparencia, la rendición de cuentas de las autoridades y la participación ciudadana en la toma de decisiones.
\end{abstract}

Palabras clave: juicios paralelos, libertad de información, independencia, imparcialidad, presunción de inocencia.

\begin{abstract}
The article explores the so-called parallel or mediatic judgments and their recognition in Chile. This, in order to discard the positions that refute its legality based on the impairment of the right to the presumption of innocence and guarantees of the independence and impartiality of the judge or court that is aware of a criminal process. As a general conclusion, it is postulated that this does not occur in hypotheses where rights and guarantees are exercised correctly, especially within an open government that promotes transparency, accountability of the authorities and citizen participation in decision-making.
\end{abstract}

Key words: parallel judgments, freedom of information, independence, impartiality, presumption of innocence.

\footnotetext{
* Doctora en Derecho por la Pontificia Universidad Católica de Chile. Profesora de Derecho Constitucional, Facultad de Derecho, Universidad Andrés Bello. Dirección postal: Bellavista 0121, Providencia, Santiago. Dirección electrónica: carmen.droguett@unab.cl.

** Doctora en Derecho por la Pontificia Universidad Católica de Chile. Profesora investigadora, Facultad de Derecho, Universidad Andrés Bello. Dirección postal: Bellavista 0121, Providencia, Santiago. Dirección electrónica: nathalie.walker@unab.cl.

Este trabajo se enmarca en el proyecto interno de investigación "Jorge Millas", DI-07-2019/JM, denominado: "Libertad de información y debido proceso en casos de interés público. Análisis de la jurisprudencia constitucional chilena, española e internacional para el establecimiento de criterios que permitan delimitar la libertad de informar en la etapa prejudicial".
} 


\section{LA IMPORTANCIA DE LA INFORMACIÓN PARA UN GOBIERNO TRANSPARENTE}

Vivimos en una sociedad de la información y, por tanto, en una sociedad dependiente de la comunicación ${ }^{1}$. En ella son fundamentales los medios de comunicación y la contribución a la participación ciudadana que éstos realizan por medio de la difusión de hechos de interés público. Sin embargo, en la práctica, solemos olvidarnos de ello e imputar a priori a los medios de comunicación la responsabilidad por el menoscabo de los derechos de quienes son partícipes de los hechos que transmiten, con el consecuente enjuiciamiento y valoración negativa de su conducta ${ }^{2}$.

Una clara muestra de lo anterior, es lo que acontece con la difusión de información vinculada a ilícitos penales y, en particular, aquella que involucra a funcionarios públicos y a personas con connotación pública (e incluso, sin ella) ${ }^{3}$. Así sucedió, por ejemplo, con las circunstancias en que se vio envuelta la doctora María Luisa Cordero en el año 2013, quien, en el marco de la realización de un programa de televisión sobre licencias falsas fue grabada -sin su consentimiento- con una cámara oculta en su oficina ${ }^{4}$. O el contexto que, en el año 2014 vinculó a Sergio Landskron a la explosión de una bomba en el Barrio Yungay de Santiago 5 . O el hecho delictual que el año 2017 provocó que una mujer perdiera sus ojos y que, posteriormente se vio expuesta a que un programa de televisión diera a conocer

\footnotetext{
1 SÁNCHeZ (1996) p. 7.

${ }^{2}$ En este punto, cabe destacar la opinión de Tomás Aliste Santos, quien afirma que "[h]allar certeza en el aluvión de afirmaciones factuales que la industria de los mass media y las redes comunicativas vertiginosamente producen a cada instante es empresa harto dificultosa en nuestro tiempo, $y$, ciertamente la verdad ha ido progresivamente diluyéndose en un modelo informativo globalizado en el cual el fin que orienta el mensaje ya no es tanto ofrecer información veraz como ofrecer a la opinión pública un relato persuasivo en torno a los hechos sin que necesariamente se infiera en adecuada relación de correspondencia” ALISTE (2018) p. 42.

${ }^{3}$ Un interesante estudio sobre la estructura general utilizada por los periódicos para ordenar información, puede verse en ORSI (2018) pp. 59-100.

${ }^{4}$ En este sentido, véase el lead y notas vinculadas a la Sra. Cordero publicadas en los sitios electrónicos que a continuación se indican: "Doctora Cordero no se 'averguenza", www.lanacion.cl (13/08/2003). Disponible en: http://lanacion.cl/2003/08/13/doctora-cordero-no-se-averguenza/. Fecha de consulta: 7 de mayo de 2019. "Colegio médico expulsa a doctora Cordero"; www.emol.com (12/06/2004). Disponible en: https://www.emol. $\mathrm{com} /$ noticias/nacional/2004/06/11/150060/colegio-medico-expulsa-a-doctora-cordero.html. Fecha de consulta: 7 de mayo de 2019. "El triste prontuario de la doctora Cordero"; www.radiozero.cl (08/07/2017). Disponible en: https://www.emol.com/noticias/nacional/2004/06/11/150060/colegio-medico-expulsa-a-doctoracordero.html. Fecha de consulta: 7 de mayo de 2019.

${ }^{5}$ En este sentido, véase el lead y notas vinculadas al Sr. Sergio Landskron en los sitios electrónicos que a continuación se indican: "Familiares de Sergio Landskron descartan su vínculo con 'grupo terrorista' y aseguran que fue víctima de bombazo"; www.elmostrador.cl (25/09/2014). Disponible en: https://m.elmostrador.cl/ noticias/pais/2014/09/25/familiares-de-sergio-landskron-descartan-que-estuviera-vinculado-a-grupo-terroristay-aseguran-que-fue-victima-de-bombazo/. Fecha de consulta: 7 de mayo de 2019; "Video: Captan momento en que hombre se quema tras explotar artefacto en Barrio Yungay", www.puranoticia.cl (25/09/2014). Disponible en: https://www.puranoticia.cl/front/contenido/2014/09/25/113850/video-captan-momento-en-que-hombrese-quema-tras-explotar-artefacto-en-barrio-yungay.php. Fecha de consulta: 7 de mayo de 2019; "Temor en el centro de Santiago Chile: manipulaba una bomba casera, le estalló en la cara y murió en el acto", www.elclarin. com (26/09/2014). Disponible en: https://www.clarin.com/mundo/Chile-manipulaba-casera-estallo-murio_0_ S1HSZSt9DQl.html. Fecha de consulta: 7 de mayo de 2019.
} 
detalles de su vida íntima ${ }^{6}$. O los hechos que a la fecha involucran a ex funcionarios de Carabineros de Chile con la muerte del comunero mapuche Camilo Catrillanca ${ }^{7}$. Hechos de este tipo son incluidos en periódicos de circulación nacional u otros medios escritos, en noticieros y en redes sociales, lo que provoca inmediatas reacciones en la opinión pública y que da paso al surgimiento de un juicio mediático -paralelo al desarrollo del proceso judicial- y que puede afectar derechos y garantías de quienes han protagonizado los hechos que son objeto de la información que se difunde.

La realidad nos demuestra que los juicios paralelos surgen antes de los procesos judiciales o durante su desarrollo. Es precisamente en el segundo caso, esto es, en su dimensión extraprocesal, donde -estimamos- estaría realmente su eventual compromiso con la afectación de derechos fundamentales, en cuanto podría entenderse -erróneamente- que el sujeto no contaría con garantías suficientes frente a un ejercicio de la libertad de información sobre hechos de interés público ${ }^{8}$.

En vista de lo anterior, es preciso señalar que este trabajo no aborda el análisis de las restricciones a la publicidad de la investigación respecto de terceros, del imputado y demás intervinientes para el éxito de la investigación (o las que son producto del secreto de sumario en los casos que el antiguo sistema procesal penal se mantiene vigente), ni las medidas de reserva de información. En el primer supuesto, estamos en presencia de medidas judiciales internas que forman parte del proceso - no extraprocesales- y que se encuentran expresamente regladas en el ordenamiento jurídico y, en el segundo supuesto, de excepciones legales a la publicidad que se ajustarían a los requisitos de constitucionalidad que fija el artículo $8^{\circ}$ de la Constitución chilena y que limitan el principio de publicidad. Tal es el caso de los artículos 81, 274 c), 276, 277, 361, 375, 380 y 431 del Código Orgánico de

6 En este sentido, véase notas vinculadas en los sitios electrónicos que a continuación se indican: "Nabila Rifo demandó a Canal 13, a Tonka Tomicic y al ex director de 'Bienvenidos”, www.cooperativa.cl (28/12/2017). Disponible en: https://www.cooperativa.cl/noticias/entretencion/television/canal-13/nabila-rifo-demando-a-canal-13-a-tonka-tomicic-y-al-ex-director-de/2017-12-28/163358.html. Fecha de consulta: 7 de mayo de 2019; "Nabila Rifo llega a acuerdo extrajudicial con Canal 13 tras divulgación de su ficha ginecológica”, www.elmostrador.cl (08/06/2018). Disponible en: https://m.elmostrador.cl/dia/2018/06/08/nabila-rifo-llega-a-acuerdoextrajudicial-con-canal-13-tras-divulgacion-de-su-ficha-ginecologica/. Fecha de consulta: 7 de mayo de 2019.

7 En este sentido, véase notas vinculadas al caso en los sitios electrónicos que a continuación se indican: "Los pasos del caos en el caso Catrillanca”, www.pautapunto.cl (20/12/2018). Disponible en: https://www.pauta.cl/ politica/paso-a-paso-del-caso-en-el-homicidio-camilo-catrillanca. Fecha de consulta: 7 de mayo de 2019. "Menor del caso Catrillanca 'Querí que te mate como a tu peñi', me dijeron” (11/03/2019). Disponible en: http:// lanacion.cl/2019/03/11/menor-del-caso-catrillanca-queri-que-te-mate-como-a-tu-peni-me-dijeron/. Fecha de consulta: 7 de mayo de 2019.

Si tomamos un par de buenos ejemplos del ámbito español, tenemos el caso Alcàsser, del año 1997, surgido del secuestro, violación, tortura y asesinato de tres adolescentes del municipio valenciano de Alcàsser, y el de Dolores Vásquez, del año 2003, tras su indebido procesamiento por el asesinato de Rocío Wanninkhof. Sobre el caso Alcàsser, véase "25 años del crimen de Alcàsser", www.elpais.com (13/11/2017). Disponible en: https://elpais.com/elpais/2017/11/12/album/1510500183_634784.html. Fecha de consulta: 7 de mayo de 2019. Sobre el caso de Dolores Vásquez véase "La Audiencia rechaza indemnizar con cuatro millones a Dolores Vázquez”, www.elpais.com (23/10/2012). Disponible en: https:/elpais.com/sociedad/2012/10/23/actualidad/1350994173_584629.html. Fecha de consulta: 7 de mayo de 2019. Asimismo, véase "Dolores Vázquez, un caso que sigue abierto 15 años después”, www.elmundo.es (13/10/2014). Disponible en: https://www. elmundo.es/andalucia/2014/10/13/543bb3f0ca4741a3338b4580.html. Fecha de consulta: 7 de mayo de 2019.

8 Sobre la complejidad y extensión de la que dan cuenta los juicios paralelos, véase LetUria (2018) pp. 26-29. 
Tribunales; de los artículos 92, 182, 289 y 463 del Código Procesal Penal; del artículo 86 de la Ley No 19.947, que establece la nueva ley de matrimonio civil; del artículo 28 y 29 de la Ley No 19.620, que dicta normas sobre adopción de menores y del artículo 33 de la Ley No 19.733, sobre libertades de opinión e información y ejercicio del periodismo?.

La constante difusión de información vinculada a ilícitos penales y, con ello, de datos que darán lugar a una investigación policial, así como las dudas que surgen en torno a la legalidad de los denominados "juicios paralelos" hace necesario precisar su contenido y, consecuencialmente, los límites al ejercicio de la libertad de informar. Ello, con la finalidad de descartar aquellas posturas que objetan, en todo supuesto y sin distinción, la legalidad de los juicios paralelos, producto del menoscabo de derechos.

Lo anterior resulta primordial al interior de un régimen político democrático, sobre todo si se tiene en cuenta la función que tanto el Tribunal Europeo y la Corte Interamericana de Derechos Humanos atribuyen a la libertad de información, como el deber que imponen a los Estados de interpretar restrictivamente sus límites, aún de aquellos que puedan ofender, o resultar perturbadores o chocantes ${ }^{10}$. En tal sentido, no es posible considerar como democrática a una forma de gobierno si no existe en ella una plena y efectiva participación ciudadana. Y, para participar, es fundamental tener acceso a aquella información que se estima de trascendencia pública ${ }^{11}$.

En este orden de cosas, un punto de partida implica sostener que información protegida es solo aquella que es obtenida legítimamente. Pero, ¿qué significa legítimamente? ¿Cuál es el límite de la facultad de difundir información tratándose de hechos que, atendido su interés público, darán lugar a juicios paralelos? Aun cuando nuestra Constitución otorga una acotada redacción a la libertad de información, si atendemos al reconocimiento internacional del derecho (particularmente el artículo 13 de la Convención Americana de Derechos Humanos) y la doctrina especializada -tanto nacional como comparada-, concluiremos que son tres las facultades que configuran la libertad de información: la facultad de investigar o buscar información, la facultad de difundir la información y la facultad de recibir dicha información. Entre ellas, la facultad de difundir la información es aquella que tiene relación con la potestad de los medios para propagar o compartir información de interés público, la cual, aun cuando la norma constitucional no lo restringe, es propia o característica de los profesionales de la información más que del sujeto universal o público ${ }^{12}$.

\footnotetext{
9 Una situación análoga acontece en España, donde los secretos son precisamente "datos cuya mera obtención está vetada; es decir, informaciones que el ordenamiento prohíbe que salgan del ámbito en que se producen o custodian". URÍAS (2014) p. 92.

10 Herrera Ulloa vs. Costa Rica (2004) párrs. 128 y 129; TRistán Donoso vs. Panama (2009) párr. 115; FonteVECCHIA y D'Amico vs. ARgentina (2011) párr. 47; TEDH, Caso Ligens vs. Austria (1986); Thorgeir ThorGEIRSON VS. ISLANDIA (1992); y JeRUSALEM VS. AustRIA (2001).

${ }^{11}$ En este sentido, véase, Opinión Consultiva OC-5/85 sobre la colegiación obligatoria de periodistas; HERRERA UlLOA vs. Costa RICA (2004) párrs. 112 a 116; TRISTÁn Donoso vs. PANAMA (2009) párrs. 113 a 115; CLAUde REYeS Y OtRos vS. CHILE (2006) párrs. 84 a 86; KIMEL VS. ARGENTINA (2008) párrs. 86 a 88; LÓPEZ LONE Y OTROS VS. HONDURAS (2015) párrs. 162 a 165; y OTEGI MONDRAGÓN VS. ESPAÑA (2008) párrs. 48 a 50.

12 Ortega (2017) p. 109.
} 
El contenido de los derechos fundamentales se ha ido moldeando con el progreso de la civilización ${ }^{13}$. En consecuencia, si bien antaño los medios de comunicación -y en principio la imprenta- incluían solo algunas notas relativas a los procesos judiciales -por cuanto la libertad de información era entendida de modo restringido- hoy las cosas han cambiado y son precisamente los procesos judiciales los que se incluyen en portadas de periódicos, noticieros y programas destinados a periodismo de investigación ${ }^{14}$.

Los juicios paralelos hoy son algo inevitable en todo el mundo. Es posible afirmar lo anterior, aun cuando autores como Isabel Huertas, destaquen que, en términos porcentuales, numéricamente los juicios paralelos son escasísimos ${ }^{15}$. El problema es que en Chile no existe un reconocimiento normativo expreso de los mismos, razón por la cual su legalidad debe ser examinada a la luz de la delimitación del umbral de protección de los derechos fundamentales en eventual conflicto. Para ello, es esencial sostener que el contenido de los derechos fundamentales no es ilimitado ${ }^{16}$. Con ello, somos contrarias a sostener que entre los derechos fundamentales "los hay absolutos como el derecho a la vida y a la integridad física o psíquica, cuya violación no goza de excepciones (por ejemplo, la tortura) y los hay relativos, que deben compatibilizarse con otros derechos merecedores de igual o superior tutela, en cuyo caso si se ejercitan con todas las garantías legales no cabe hablar propiamente de vulneración del derecho fundamental, sino de sacrificio" ${ }^{17}$. Para dar respuesta a las exigencias de un caso concreto, sostenemos que en Chile como en otros países, es la delimitación de la libertad de informar, y con ello el cumplimiento de los requisitos para el legítimo ejercicio del derecho, la que permite sostener la legalidad de los juicios paralelos al interior de un gobierno abierto, y defender su contribución a una democracia más participativa. Asimismo, afirmamos que una correcta delimitación de los derechos y garantías fundamentales que -se sostiene- serían menoscabados por los juicios paralelos, permite descartar aquella hipótesis que indica que cada vez que surge un juicio paralelo, tales derechos y garantías son vulnerados. De esta forma, si bien comprendemos que un ataque en contra de estos derechos "implica la sanción del inocente, afecta al sentimiento público sobre la calidad democrática y el buen funcionamiento del sistema judicial y pone en cuestión la igualdad en la aplicación de la ley" ${ }^{18}$, sostenemos que ello no ocurre necesariamente en todos los casos en que surge un juicio paralelo, ni tampoco de manera determinista e inevitable.

En base a lo anterior, esta investigación plantea la posibilidad de informar, dentro del marco legal, sobre hechos de interés público que pueden dar lugar a un futuro proceso.

13 CeA (2012) p. 52.

${ }_{14}$ Un interesante estudio sobre la agenda temática en las noticias es el que ofrecen Maureen Díaz y Claudia Mellado en Díaz y Mellado (2017). En dicho documento consideran como parte del contenido de los titulares y noticias centrales de los principales diarios y noticieros de prensa escrita, online, televisión y radio chilena del año 2015, a aquellos que se refieren a incidentes criminales, corrupción y delitos financieros, tendencias criminales, medidas de defensa ante crímenes y procesos judiciales. En el derecho español, otro interesante estudio sobre la relevancia pública en la prensa española de información vinculada a procesos penales es la de Francesc Barata. Véase Barata (2009).

15 Huertas Martín (2018) p. 413.

16 Aguilar de Luque (2014) p. 28.

17 MuÑoz (2001) p. 245.

18 Ovejero (2017) p. 435. 
Con ello, subyace la idea de reconocer derechos y garantías incluso antes del inicio de un proceso que actúan frente a terceros - a una sociedad que busca culpable y reparación-, que protegen la celebración más tarde de un juicio justo y que amparan a las personas de sufrir injustamente una limitación indebida de sus derechos y garantías.

Delimitar un derecho es establecer su contenido ${ }^{19}$. Esto es, precisar las facultades, límites y garantías que comprende. En consecuencia, la metodología a utilizar se iniciará por la conceptualización del juicio paralelo, para luego formular los argumentos que nos permitan descartar la hipótesis que sostiene la inevitable afectación extraprocesal del derecho fundamental a la presunción de inocencia ${ }^{20}$ y de las garantías procesales de independencia e imparcialidad, en todos los casos en que un medio de comunicación informa hechos de interés público vinculados a ilícitos producto de los cuales surge un juicio paralelo. En nuestra opinión, es dicho análisis el que permite a la vez amparar a los ciudadanos al margen de los procesos judiciales y fomentar la difusión de información de interés público para la sociedad. Esto es, la difusión y acceso de los ciudadanos a información relevante o beneficiosa para toda la sociedad y no simplemente de interés individual, pues será esta información la que en un gobierno abierto nos permitirá conocer y ejercer control sobre el correcto desempeño de las funciones de las autoridades.

\section{HACIA UN CONCEPTO DE JUICIOS PARALELOS}

Sin perjuicio del concepto que al final de este acápite proponemos, es posible sostener que un juicio paralelo es el seguimiento que las personas efectúan de ciertos hechos de eventual carácter ilícito e interés público, que son difundidos por los medios de comunicación (informativo e interpretativo) y los discernimientos que a partir de estos hechos las personas se forman.

Producto de lo anterior, postulamos que el tiempo a considerar como parte de un juicio paralelo es aquel que media entre la comisión del ilícito y la obtención de la cosa juzgada o término del proceso. Esto, aun cuando nuestra atención estará centrada principalmente en el período de tiempo previo al inicio del proceso. De esta forma, excluiremos como parte del concepto la información sobre procesos terminados, pues entendemos que en dichos casos la apreciación que la sociedad efectúa de los hechos como consecuencia del ejercicio de la libertad de informar, no puede incidir en un castigo arbitrario o abusivo impuesto a las personas objeto de investigación, sino que más bien en otros derechos, tales como el derecho al olvido. Tal es la idea presente en el artículo $9^{\circ}$ de la Declaración de Derechos del Hombre y el Ciudadano de 1789, en orden a no ser castigado sin que exista antes un juicio justo, pues es solo dicho proceso el que asegura a la persona un correcto ejercicio del poder punitivo. Asimismo, en atención a que consideramos que el derecho ejercitado es el derecho a la libertad de información -cuyo objeto son hechos verdaderos

\footnotetext{
19 Nogueira (2005b) p. 20.

20 En España, el Tribunal Constitucional ha considerado muy tempranamente a la presunción de inocencia como un derecho fundamental, de carácter vinculante y con eficacia inmediata en el ámbito jurisdiccional. Ruiz-Rico y Carazo (2013) p. 398.
} 
de relevancia pública- y no la libertad de expresión, excluiremos del concepto como género periodístico, la comunicación de opinión (editorial, columnas, cartas al director, ensayos y artículos).

La doctrina nacional y comparada conceptualiza, con distintos matices y valoración, a los juicios paralelos. Así, por ejemplo, Joaquín Urías sostiene que ellos describen a aquellas "informaciones con las que se busca poner en marcha una discusión pública acerca de la culpabilidad o inocencia del acusado, así como del resto de circunstancias de un proceso en curso" 21 . Por su parte, Cristina San Miguel, señala que lo que caracteriza a los juicios paralelos es el "afectar derechos fundamentales que, teniendo su origen en el proceso, pueden verse vulnerados por la cobertura informativa de los medios de comunicación" ${ }^{22}$.

No compartimos la opinión de estos autores, pues estimamos que cuando la libertad de informar es ejercida dentro del umbral de protección que asegura nuestra Constitución en su artículo 19 No 12, los juicios paralelos no tienen por finalidad exponer la culpabilidad o inocencia de una persona, como tampoco la característica de afectar derechos fundamentales, sino que más bien la difusión de hechos de interés público. Sí compartimos la opinión de Francisco Leturia, para quien todo juicio paralelo requiere de la existencia de un proceso judicial, entendido en sentido amplio. De esta forma, éste "abarcará la etapa judicial propiamente tal, la de sumario, e incluso el tiempo que transcurre entre la comisión del delito y el inicio de cualquier investigación oficial"23.

Tratándose del período de tiempo a considerar, coincidimos también con Cristina Pauner, para quien un juicio paralelo es un "conjunto de informaciones y noticias, acompañadas de juicios de valor más o menos explícitos, publicados o difundidos durante un determinado período de tiempo en los medios de comunicación social sobre un caso sub iudice, con independencia de la fase procesal en que se encuentre" 24 . Sin embargo, es necesario hacer una precisión sobre este último concepto, pues aun cuando el Tribunal Constitucional español en su sentencia 29/2009 ha enfatizado que en la práctica es difícil distinguir libertad de información de libertad de expresión, el mismo órgano ha indicado que los juicios de valor no forman parte del ejercicio de la libertad de información, sino de la libertad de expresión, toda vez que el objeto de la libertad de información son los hechos de interés público o noticiables ${ }^{25}$. De esta forma, excluimos del concepto los juicios de valor, sean explícitos o implícitos.

Ángel Juanes, por su parte, sostiene que los juicios paralelos son "asuntos penales, civiles o de otra índole, pendientes de ser juzgados, a los que los medios de comunicación social someten a comentarios, valoraciones, apreciaciones y opiniones diversas con virtualidad suficiente para crear una opinión pública sobre el hecho, adversa o favorable, pudiendo originarse un conflicto entre el derecho a la libertad de información, de una parte, y los derechos constitucionales al honor, a la intimidad, la propia imagen $y$, especialmente, el

\footnotetext{
21 URÍAS (2014) p. 100.

22 SAN Miguel (2018) p. 374.

23 Leturia (2017) p. 27.

24 Pauner (2014) p. 92.

25 STC 6/1988, Fj. 5.
} 
derecho a la presunción de inocencia, de otra" ${ }^{26}$. Lo anterior es importante, pues si bien en la mayoría de los casos -estimamos- será la información que dice relación con eventuales delitos la que será considerada de interés público, los juicios paralelos pueden surgir en el marco de procedimientos de distinta naturaleza.

Un interesante punto es el que nos entrega Frank Harbottle, para quien, cuando se está frente a un juicio paralelo, es porque existe un inadecuado ejercicio de la libertad de prensa $^{27}$. En el mismo sentido se pronuncia Ana Oviedo, quien afirma que las más importantes violaciones de la presunción de inocencia se encuentran asociadas a los juicios paralelos, los que define como "una forma de enjuiciamiento público de conductas socialmente reprobables, que se celebran al margen del exclusivo y excluyente poder del Estado" 28 . No coincidimos con dicho criterio, pues -como examinaremos- el surgimiento de un juicio paralelo no es sinónimo de un ejercicio impropio de la libertad de informar. Por el contrario, consideramos que ellos pueden perfectamente ser el resultado de un correcto ejercicio de tal libertad, siempre y cuando se respete el contenido esencial y el marco constitucional de los derechos y garantías que reconoce la Constitución. De esta forma, solo estaremos frente a un inadecuado ejercicio de la libertad de informar en aquellas hipótesis donde no se cumpla con los requisitos de veracidad e interés público exigidos por la Constitución para el legítimo ejercicio de la libertad de información, o bien, cuando no se cumplan los requisitos que configuran el contenido del derecho a la presunción de inocencia o de las garantías procesales de independencia e imparcialidad ${ }^{29}$.

En el ámbito de la jurisprudencia internacional, es posible sostener que tanto para el Tribunal Europeo de Derechos Humanos como para la Corte Interamericana de Derechos Humanos, los juicios paralelos se encuentran inmersos en el marco de la legalidad. Esto se infiere, por ejemplo, a partir del caso The Sunday Times contra Reino Unido de 1979, también conocido como el caso de la talidomida ${ }^{30}$. Éste tiene su origen en la demanda contra el Reino Unido de Gran Bretaña e Irlanda del Norte, efectuada por el editor, el redactor jefe y un grupo de periodistas del semanario británico, tras la prohibición, impuesta al periódico por la Cámara de los Lores, de publicar un artículo que describía la historia de un laboratorio británico que había fabricado y distribuido medicamentos que contenían talidomida, sustancia que causaba defectos en recién nacidos de madres que habían utilizado este medicamento durante el estado de gravidez. La prohibición de la Cámara de publicar un proceso pendiente de resolución, se fundó en la necesidad de garantizar la autoridad e imparcialidad del poder judicial, que consideraban un límite a las libertades de expresión e información en conformidad lo dispuesto en el artículo 10.2 del Convenio Europeo para

\footnotetext{
26 JUANES (2007) p. 70.

27 Harbottle (2017) p. 9.

28 Oviedo (2017) p. 434.

29 En cuanto a la necesaria imparcialidad del juez que conoce de un asunto, cabe recordar la apreciación de Piero Calamandrei, quien sostenía que aquel debía ser un tercero totalmente extraño a la contienda, que no compartiera los intereses ni participara de las pasiones que mueven a los contendores. En tal sentido, "el interés que lo mueve es un interés superior, de orden colectivo, el interés de que la contienda se resuelva civil y pacíficamente". Calamandrei (1960) p. 60.

30 Sunday Times vs. REINO UNIDO (1979).
} 
la Protección de Derechos Humanos y de las Libertades Fundamentales. En su sentencia, el Tribunal Europeo analizó el deber de reserva de los medios de comunicación tratándose de información vinculada a procesos judiciales. En su decisión constató, asimismo, la imprecisión de la norma en que la Cámara había fundado su decisión y declaró que las limitaciones a las libertades de expresión e información deben ser interpretadas restrictivamente, teniendo presente el interés público de la información para la población y su derecho a recibirla. Con ello -entendemos-, el Tribunal destacó la importancia de los medios de comunicación -en especial de la prensa escrita- en la formación de la opinión pública en materias de interés público ${ }^{31}$.

$\mathrm{Al}$ interior del Sistema Interamericano de Protección de Derechos Humanos, una interesante sentencia de la Corte Interamericana de Derechos Humanos es la del caso Herrera Ulloa v. Costa Rica ${ }^{32}$. En ella, la Corte enfatizó la importancia de la función de los medios de comunicación para el ejercicio de la dimensión social de la libertad de pensamiento y expresión en una sociedad democrática, y su responsabilidad en la función social que desarrollan. Asimismo, destacó el valor de la imparcialidad del juez como uno de los presupuestos fundamentales del debido proceso. En consecuencia, que el juez se aproxime a los hechos de la causa de modo imparcial, permite a los tribunales inspirar la confianza necesaria a las partes del caso y a la sociedad ${ }^{33}$.

De todo lo anterior, es posible extraer dos conclusiones. La primera, es que en el análisis de legalidad de los juicios paralelos, la atención no debe enfocarse en los datos que son recogidos, sino que en la forma y el momento en que ellos son difundidos por un medio de comunicación. Lo que verdaderamente importa es la forma y la oportunidad en que el medio de comunicación da cuenta a la ciudadanía de un determinado hecho. En cuanto a la forma -como veremos- la difusión debe cumplir con los requisitos de veracidad e interés público exigidos para un legítimo ejercicio de la libertad de información. Tratándose del momento, será importante que la difusión se produzca en el tiempo que media entre la comisión del eventual ilícito y el término del proceso judicial. La segunda conclusión o consecuencia es que, en principio, los juicios paralelos son legales y necesarios, debido al significado que tiene el ejercicio de la libertad de información al interior de una sociedad democrática y la función de los medios de comunicación para el ejercicio de la dimensión social del derecho, esto es, para el intercambio de informaciones entre las personas, facultándolas a comunicar y conocer otros los puntos de vista.

De esta manera, frente a la pregunta acerca de si se puede prohibir preventivamente informar sobre asuntos que eventualmente serán sometidos a un proceso judicial, tal como afirma Joaquín Urías, es evidente que tal construcción es difícil defender en un sistema que reconoce y ampara la libertad de información ${ }^{34}$. Sin embargo -hemos indicado- el surgimiento de un juicio paralelo no siempre se acompaña de un inadecuado ejercicio de la libertad de información. Por ello, es fundamental precisar las hipótesis de restricción al ejer-

\footnotetext{
31 SuNDAY TIMES VS. REINO UNIDO (1979) párr. 65.

32 Herrera Ulloa vs. Costa Rica (2004).

33 Herrera UlLoA vs. Costa Rica (2004) párrs. 117 y 171.

34 URÍAS (2014) p. 100.
} 
cicio de este derecho, ya que si bien nuestra Constitución asegura a todas las personas en su artículo 19 No 12 la libertad de emitir opinión y de informar sin censura previa, la Carta Fundamental también garantiza el derecho a la presunción de inocencia y las garantías procesales de independencia e imparcialidad del juez o tribunal. Tales normas son vinculantes para gobernantes y gobernados, en virtud del principio de supremacía constitucional y juridicidad, que consignan respectivamente los artículos $6^{\circ}$ y $7^{\circ}$ de la Constitución chilena de $1980^{35}$. Por ende, son obligatorias para todo aquel que ejerce la libertad de información y por cualquier medio, comprendidos los medios de comunicación.

Nos resta, entonces, proponer un concepto de juicio paralelo. Al respecto, diremos que éste consiste en el seguimiento y discernimiento que las personas efectúan de hechos eventualmente sub iudice y de interés público, que han sido informados por medios de comunicación informativos e interpretativos, en el tiempo que media entre el inicio de una investigación y la etapa judicial propiamente tal; los cuales -luego de un tiempo-contribuyen a la formación de una opinión pública libre e informada. Dicho concepto se ajusta al parámetro de publicidad que, en palabras de Miguel Carbonell, es una nota omnipresente en los procesos judiciales, sin desconocer la importancia para la sociedad de una libertad de información correctamente ejercida ${ }^{36}$. Asimismo, se ajusta a la idea formulada por Beccaria, en orden a que " $[\mathrm{u}] \mathrm{n}$ hombre no puede ser llamado reo antes de la sentencia del juez, ni la sociedad puede quitarle la pública protección, sino cuando esté decidido que ha violado los pactos bajo que le fue concedida" ${ }^{37}$.

\section{ARGUMENTOS PARA RECHAZAR LAS HIPÓTESIS QUE CUESTIONAN LA LEGALIDAD DE LOS JUICIOS PARALELOS POR AFECTAR EL DERECHO A LA PRESUNCIÓN DE INOCENCIA Y LAS GARANTÍAS DE INDEPENDENCIA E IMPARCIALIDAD DEL JUEZ}

No hay duda de que la libertad de información es un bien que la sociedad debe defender y cuidar $^{38}$. Sin embargo, la forma en que este derecho es ejercido por los medios cuando se trata de información de interés público origina el surgimiento de un juicio paralelo, que puede menoscabar derechos o garantías. Tal como indicamos con anterioridad, ello sucederá en las hipótesis de inadecuado ejercicio de la libertad de informar hechos de relevancia pública; o cuando no se cumplan los requisitos de veracidad e interés público exigidos por la Constitución para el legítimo ejercicio de la libertad de información; o bien, no se verifiquen los requisitos que configuran el contenido del derecho a la presunción de inocencia o de las garantías procesales de independencia e imparcialidad. En efecto, constituyen limitaciones clásicas a la facultad de informar: el respeto de los derechos a la honra, a la intimidad, a la vida privada, a la propia imagen, a la presunción de inocencia y las garantías procesales vinculadas al funcionamiento del Estado, tales como la independencia e im-

\footnotetext{
35 CEA (2013) p. 48.

36 Carbonell (2009) p. 54.

37 BeCCARia (2015) p. 39.

38 Barata (2009) p. 219.
} 
parcialidad del tribunal ${ }^{39}$. Por su parte, para un legítimo ejercicio del derecho a informar, son requisitos el interés público y la veracidad de la información ${ }^{40}$.

Tratándose de los límites a la libertad de información, si bien el artículo 19 No 12 de la Constitución Política de la República reconoce a toda persona la facultad de informar, establece un ejercicio limitado del derecho, pues la norma indica que éste es sin perjuicio del deber de responder de los delitos y abusos que se cometan en el ejercicio de dicha libertad, en conformidad a la ley. Tales delitos y abusos son, en la práctica, hipótesis de afectación al contenido esencial de otros derechos y garantías reconocidas y amparadas por la normativa nacional y por disposiciones de instrumentos internacionales ratificados por Chile, que se encuentren vigentes.

En cuanto a los derechos que actúan como límites a la libertad de información, examinaremos el derecho a la presunción de inocencia y las garantías procesales de independencia e imparcialidad, en el entendido que su menoscabo por un juicio paralelo -bajo determinados supuestos- puede conducir a la aplicación de una pena arbitraria a los sujetos vinculados a la información que se difunde. El objetivo, por tanto, es establecer hasta qué punto los medios de comunicación pueden difundir información de interés público sin influir en la actividad jurisdiccional y sin afectar derechos fundamentales.

En consecuencia, pretendemos reflexionar en torno a la búsqueda de un equilibrio entre el ejercicio de la libertad de informar y el respeto a los derechos y garantías procesales. En esa línea, estimamos que existe a lo menos un importante argumento que permite descartar la convicción a priori de su inevitable afectación de los derechos de índole procesal producto de los juicios paralelos que surgen tras la difusión de hechos de interés público por los medios: a saber, que tanto el derecho a la presunción de inocencia como las garantías de inocencia e imparcialidad son fundamentales para un Estado de Derecho y, por tal razón, cuentan con un reconocimiento normativo que debe ser respetado e interpretado, tomando en cuenta sus límites y requisitos. Se trata de normas obligatorias para gobernantes y gobernados, y su contenido esencial -tal como sucede con la libertad de informaciónes vinculante para todos.

En materia de presunción de inocencia, para condenar se requiere tener certeza de culpabilidad $^{41}$. Sólo a partir de dicho convencimiento, obtenido a partir de la valoración de la prueba se puede condenar ${ }^{42}$. De esta forma, la consagración de la presunción de inocencia como derecho fundamental proscribe la condena en la duda, pues establece como hecho inicial y cierto la inocencia del sujeto. La presunción de inocencia es, así, el derecho

39 En este sentido, véase Pauner (2014), Ovejero (2017) y Barata (2009).

40 Iglesias (2011) p. 231.

41 En tal sentido, "el tribunal adquiere la certeza objetivamente a través de la prueba rendida en el proceso aplicando los principios de la lógica, las máximas de la experiencia y los conocimientos científicamente afianzados, y dicha convicción la externaliza a través de la sentencia, para que pueda ser controlada”. MaturanA y MONTERO (2012) Tomo II, p. 805.

42 Tomas y Valiente (1987) p. 25. 
o garantía de seguridad, conforme al cual la ley tiene como un hecho cierto la exoneración de culpa del sujeto, mientras no exista sentencia condenatoria ${ }^{43}$.

En Chile, la presunción de inocencia forma parte del bloque constitucional de derechos $^{44}$ y se incorpora por medio del artículo $5^{\circ}$ inciso segundo de la Constitución y por los artículos 8.2 de la Convención Americana de Derechos Humanos y 14.2 del Pacto Internacional de Derechos Civiles y Políticos, todos los cuales determinan que una persona es inocente hasta que se pruebe su culpabilidad y, a su vez, limitan la soberanía del Estado.

El artículo $5^{\circ}$ inciso segundo de la Constitución establece como límite al ejercicio de la soberanía -al poder político de un Estado- los derechos esenciales de la persona humana. Producto de lo anterior, indica la norma, es deber de los órganos del Estado el respetar y promover tales derechos, garantizados por la Constitución, "así como por los tratados internacionales ratificados por Chile y que se encuentren vigentes”. A ello cabe agregar el reconocimiento implícito de la presunción de inocencia que efectúa el artículo 19 No 3 inciso sexto de la Constitución, conforme al cual "[1]a ley no podrá presumir de derecho la responsabilidad penal”.

Asimismo, en el rango legal, conviene citar el artículo $4^{\circ}$ del Código Procesal Penal, que indica con claridad los límites y alcances del ius puniendi, pues afirma que "[n]inguna persona será considerada culpable ni tratada como tal en tanto no fuere condenada por una sentencia firme". Por su parte, el artículo $7^{\circ}$ del mismo Código dispone que "[l]as facultades, derechos y garantías que la Constitución Política de la República, este Código y otras leyes reconocen al imputado, podrán hacerse valer por la persona a quien se atribuyere participación en un hecho punible desde la primera actuación del procedimiento dirigido en su contra y hasta la completa ejecución de la sentencia. Para este efecto, se entenderá por primera actuación del procedimiento cualquiera diligencia o gestión, sea de investigación, de carácter cautelar o de otra especie, que se realizare por o ante un tribunal con competencia en lo criminal, el Ministerio Público o la policía, en la que se atribuyere a una persona responsabilidad en un hecho punible". De esta forma y en cumplimiento de lo anterior, desde la primera actuación del procedimiento -aun cuando sea de naturaleza cautelar- desplegada por el tribunal, el Ministerio Público o la policía, la ley chilena tiene por cierta la inocencia de la persona.

Consecuencialmente, está prohibida toda presunción de culpabilidad ${ }^{45}$. El derecho a la presunción de inocencia tiene por objeto evitar los juicios condenatorios anticipados en contra del imputado sin contar con pruebas para ello ${ }^{46}$. Asimismo, este derecho impide

\footnotetext{
43 Nogueira (2012) p. 191. Desde una perspectiva constitucional y en el ordenamiento español, el derecho a la presunción de inocencia "comporta el derecho a ser condenado solo mediante pruebas de cargo obtenidas con las debidas garantías, de manera que queden acreditados a través de una argumentación razonable todos los elementos fácticos del hecho punible, la intervención del acusado en el mismo, y el elemento subjetivo consistente en el vínculo entre los hechos probados y la intención que se perseguía con su realización. RuIz-RICO y CARAzO (2013) p. 400.

44 Nogueira (2005b) p. 221.

45 Maturana y Montero (2012) Tomo I, p. 29.

46 Nogueira (2012) p. 191.
} 
establecer la responsabilidad de una persona sin la existencia de una sentencia fundada y congruente $e^{47}$.

Lo anterior -estimamos- sugiere dos importantes consecuencias: la primera es que la carga de la prueba de la culpabilidad de un sujeto recae en el Estado; mientras que la segunda consecuencia es que todo imputado debe ser tratado como inocente hasta que no exista sentencia condenatoria firme en su contra. De tal manera que constituye un deber del medio de comunicación que informa sobre una investigación en curso, o que aún no se ha iniciado, no presumir -o asumir- la culpabilidad de las personas que participan de los hechos de interés público. En tal sentido, sea o no cuestionado el derecho a la presunción de inocencia por los medios de comunicación, es un derecho que no puede ser quebrantado por la difusión informativa, ya que "solo los órganos jurisdiccionales $-\mathrm{y}$, en su caso, la autoridad administrativa sancionadora-podrían originar tal menoscabo" ${ }^{48}$. Algunas medidas que podrán adoptarse serán, por ejemplo, no considerar la formalización como juzgamiento, no tratar a las personas como condenados ante la opinión pública y el transmitir objetivamente $-\mathrm{y}$ con la conveniente mesura- las detenciones y otras diligencias policiales efectuadas contra la persona del imputado. Para ello, es importante tener a la vista las resoluciones del Consejo de Ética de los Medios de Comunicación. Por ejemplo, la Resolución No 220, en donde el Consejo recomendó a los medios de comunicación "examinar con el mayor cuidado los antecedentes presentados por sus fuentes a fin de no cometer errores que puedan confundir al público o que éste llegue a interpretar equivocadamente los hechos informados, y eventualmente causar daño a quienes aparecen aludidos” ${ }^{49}$.

Por su parte, la independencia e imparcialidad de los jueces y tribunales son garantías fundamentales para asegurar el debido control de la actividad jurisdiccional. En ese sentido, Couture expresaba que la garantía constitucional de la tutela del proceso exige la concurrencia, al menos, de tres condiciones: "independencia, para que el juez pueda hallarse por encima de los poderes políticos y aún de las masas que pretenden presionar sobre las decisiones; autoridad, para que sus fallos no sean dictámenes académicos ni piezas de doctrina, y se cumplan efectivamente por los órganos encargados de ejecutarlos; y responsabilidad, para que el poder no se convierta en despotismo" 50 .

Tal como sostiene Andrés Bordalí, el reconocimiento del principio de separación de poderes es un postulado básico de un Estado de Derecho, producto del cual "los jueces son independientes de los poderes políticos e independientes respecto de todos los demás jueces y tribunales" ${ }^{51}$. Esta es la idea que se encuentra detrás del artículo 76 de la Constitución chilena, norma que -junto con proporcionar un concepto de jurisdicción-indica que la función judicial recae exclusivamente en los tribunales establecidos por el legislador.

La independencia y la imparcialidad de los jueces y tribunales se encuentran reconocidas en el artículo 19 No 3 inciso sexto de la Constitución, norma de carácter vinculante

\footnotetext{
47 Maturana y Montero (2012) Tomo I, p. 31; Maturana y Montero (2012) Tomo II, p. 800.

48 Huertas (2018) p. 416.

49 Consejo de Ética Medios de Comunicación. Resolución No 220.

50 Couture (2010) p. 143.

51 Bordalí (2013) p. 609.
} 
para todos y que asegura a todas las personas un proceso y una investigación racionales y justos. Con ello, implícitamente, consigna el derecho a un debido proceso, pues no existe en Chile ninguna disposición constitucional que lo reconozca de manera expresa ${ }^{52}$. Así, la norma establece que "[t]oda sentencia de un órgano que ejerza jurisdicción debe fundarse en un proceso previo legalmente tramitado. Corresponderá al legislador establecer siempre las garantías de un procedimiento y una investigación racionales y justos”.

La falta de reconocimiento expreso del debido proceso no obedece a un olvido del constituyente, sino que a su deseo de no utilizar una denominación que tiene sus orígenes en el derecho anglosajón (due process of law), por cuanto ello podría haberse interpretado como una obligación para los operadores jurídicos nacionales a interpretar la garantía en conformidad a lo indicado por la doctrina y jurisprudencia anglosajonas ${ }^{53}$. La expresión de debido proceso fue intencionalmente excluida de la norma, a fin de no trasladar los conflictos interpretativos estadounidenses al derecho interno ${ }^{54}$. Por esa razón, el constituyente de 1980 optó, en el artículo 19 No 3, por la expresión de "racional y justo procedimiento" y es en dicha garantía en donde debe ser incorporado el reconocimiento del debido proceso como derecho fundamental de las personas ${ }^{55}$.

Para la Comisión de Estudio de la Nueva Constitución, el derecho al debido proceso se integra por garantías tales como el emplazamiento de las partes, el examen y objeción de la prueba rendida, la existencia de recursos procesales, y la fundamentación de las sentencias. Sin embargo, el debido proceso no comprende solo garantías ${ }^{56}$ vinculadas a la dimensión procesal de la justicia, sino que también a aquellas que tradicionalmente han formado parte de un debido proceso (derecho a la defensa y a un juez predeterminado por ley) y a aquellas que se incorporan por estar reconocidas en tratados internacionales ratificados por Chile y vigentes en virtud de lo indicado en el ya citado artículo 5 inciso segundo ${ }^{57}$.

Entre estas garantías del debido proceso reconocidas por tratados internacionales se encuentran, precisamente, las garantías de independencia e imparcialidad del juez o tribunal, que reconoce la Declaración Universal de Derechos Humanos en su artículo 10, la Convención Americana de Derechos Humanos en su artículo 8.1 y el Pacto Internacional de Derechos Civiles y Políticos en su artículo 14.1. En el Sistema de Naciones Unidas, el artículo 10 de la Declaración Universal de Derechos Humanos dispone que "[t]oda persona tiene derecho, en condiciones de plena igualdad, a ser oída públicamente y con justicia por un tribunal independiente e imparcial, para la determinación de sus derechos y obligaciones o para el examen de cualquier acusación contra ella en materia penal”. Mientras que,

\footnotetext{
52 García (2013) p. 230 y Cea (2012) pp. 127 y 182).

53 Bordalí (2009) p. 265. Esto ya era reconocido por el procesalista Eduardo Couture, al señalar que: "La Suprema Corte de los Estados Unidos ha sostenido que es garantía fundamental la existencia de un tribunal 'competente e imparcial' y que viola la garantía del due process of law la existencia de un juez inferior que cobra sus servicios solo cuando condena al demandado y no cuando lo absuelve”. Couture (2010) p. 143.

54 Bordalí (2009) p. 265; García (2013) p. 236.

55 Bordalí (2009) p. 265; Bordalí, Cortéz y Palomo (2013) pp. 30 y 31; Maturana y Montero (2012)

Tomo I, p. 30; Nogueira (2003) p. 170.

56 CENC, sesiones $101^{\mathrm{a}}$ a $103^{\mathrm{a}}$.

57 Bordalí (2009) p. 266.
} 
el artículo 14.1 del Pacto Internacional de Derechos Civiles y Políticos, señala que "[t]odas las personas son iguales ante los tribunales y cortes de justicia. Toda persona tendrá derecho a ser oída públicamente y con las debidas garantías por un tribunal competente, independiente, imparcial, establecido por la ley, en la substanciación de cualquier acusación de carácter penal formulada contra ella o para la determinación de sus derechos u obligaciones de carácter civil”. Por su parte, al interior del Sistema Interamericano, el artículo 8.1 de la Convención Americana establece que "[t]oda persona tiene derecho a ser oída, con las debidas garantías y dentro de un plazo razonable, por un juez o tribunal competente, independiente e imparcial, establecido con anterioridad por la ley, en la sustanciación de cualquier acusación penal formulada contra ella, o para la determinación de sus derechos y obligaciones de orden civil, laboral o de cualquier otro carácter”.

Es en este último sentido que se ha pronunciado también la Corte Interamericana de Derechos Humanos, órgano que en su sentencia recaída en el caso Palamara vs. Chile ${ }^{58}$, consideró que el derecho a ser oído por un juez o tribunal independiente e imparcial es una garantía fundamental de un debido proceso $^{59}$. Lo anterior -compartimos-, equivale a sostener que es una exigencia para nuestro Estado el asegurar que el juez o tribunal, en el ejercicio de la función que desempeña, cuente con la mayor objetividad para enfrentar el proceso ${ }^{60}$.

Tal opinión coincide con la del Tribunal Europeo de Derechos Humanos, que ha examinado la garantía de imparcialidad de los jueces a propósito del artículo 6.1 del Convenio Europeo, instrumento que reconoce a toda persona el derecho "a que su causa sea oída equitativa, públicamente y dentro de un plazo razonable, por un Tribunal independiente e imparcial, establecido por ley". En su jurisprudencia, dicho tribunal distingue entre el deber de imparcialidad subjetivo y objetivo. De acuerdo al criterio subjetivo, la convicción o interés personal del juez debe ser ajena a la causa, y no deben existir sospechas objetivas y justificadas que permitan temer que, respecto del caso concreto el juez utilizará un criterio de juicio apartado a lo dispuesto por el ordenamiento jurídico ${ }^{61}$. En un sentido objetivo, en cambio, la imparcialidad se traduce en precisar si el juez ofrece las garantías suficientes para excluir cualquier duda razonable ${ }^{62}$. En el sentido subjetivo, el tribunal considera que la imparcialidad personal de un magistrado se presume hasta que se prueba lo contrario $^{63}$. Por su parte, en el sentido objetivo, el tribunal estima que con independencia de la actitud personal del juez, existen ciertos hechos verificables que autorizan a dudar de su imparcialidad ${ }^{64}$.

Sin embargo, la frontera entre ambas nociones no es hermética y los juicios paralelos -en principio- dificultan la aplicación de la garantía de imparcialidad. Es por ello que algunos autores afirman que, en el marco del ejercicio de la libertad de información ejercida

58 Palamara Iribarne VS. Chile (2005).

59 Palamara Iribarne VS. Chile (2005) párr. 185.

60 CEA (2012) p. 182.

61 Así también lo exponen Maturana y Montero (2012) Tomo II, p. 805.

62 Piersack CONTRA BÉlgiCA (1982) párr. 30 y Gómez de Liaño y Botella CONTRA España (2008) párrs. 60 a 62.

63 Affaire Kyprianou contra Chypre (2005) párr. 119; Ruiz-Rico y Carazo (2013) p. 281.

64 Affaire Kyprianou contra Chypre (2005) párr. 118. 
por los medios de comunicación, los juicios paralelos crean prejuicios sociales que pueden llegar a influir en las decisiones de los jueces a cargo de las causas ${ }^{65}$.

Nuestra opinión se orienta en sentido contrario y ello obedece a que la imparcialidad del juez no es una condición que pueda ser exigida a toda persona -como, por ejemplo, a los medios de comunicación - sino que exclusivamente frente al juez que conoce de la causa, encargado de decidir la inocencia o culpabilidad del imputado. De esta forma, no es viable invocar el menoscabo de esta garantía por el solo hecho de dar lugar, a través de la noticia, a un debate público paralelo, previo al inicio del proceso. Ello solo será posible cuando exista, de parte del órgano llamado a resolver, una evidente animadversión en contra de la persona que es sujeto pasivo de la investigación o acusación. Es solo en este contexto en donde se produce el riesgo de que los juicios paralelos produzcan lo que casi todos temen, esto es, que "la influencia que las valoraciones y opiniones en ellos expresadas puedan tener sobre la decisión judicial que finalmente se adopte" ${ }^{66}$.

En atención a lo expuesto, puede concluirse que es deber del medio de comunicación que informa sobre una investigación en curso (o que aún no se ha iniciado) el abstenerse de difundir hechos por medio de formas que induzcan a temer que, en el caso concreto, el juez utilizará un discernimiento de reflexión lejano a lo dispuesto por el ordenamiento jurídico. Para ello, es fundamental el deber legal -que pesa sobre quien informade cumplir con los requisitos para que el ejercicio de su derecho se encuentre amparado por la norma constitucional que lo reconoce. Tal como se indicó previamente, dichos requisitos son el interés público y la veracidad de la información. Más aún, tendrá preponderancia el segundo requisito, por cuanto es presumible que una información vinculada a una conducta ilícita atañe a la comunidad y, por ende, será de interés o relevancia pública. Como afirma Muñoz-Torres, el interés público de la información no es algo puramente caprichoso, subjetivo o irracional, sino que se trata de temas que siempre interesan a las personas, en mayor o menor grado ${ }^{67}$. De esta forma, una conducta ilícita es información de interés público no por capricho de la prensa, sino que porque su difusión puede, por ejemplo, dar cuenta del grado de cumplimiento del deber de fiscalización y prevención del delito de distintas autoridades. En el contexto de una noticia, la referencia a lo personal, su actualidad, prominencia, conflicto y repercusiones futuras, son elementos básicos que debe reunir un hecho para ser calificado como información de interés público ${ }^{68}$.

El principal problema de los juicios paralelos radica en que, con frecuencia, las exigencias señaladas no se cumplen y los medios de comunicación publican informaciones sesgadas y parciales, configurándose no solo un incumplimiento al deber de veracidad, sino que también un ataque constante y extendido en el tiempo en contra de los sujetos de una investigación asociada a un proceso judicial y/o que participan de la información que se difunde. Producto de ello, sostenemos que la valoración y crítica por los medios de comunicación de un proceso judicial pendiente de resolución judicial o no iniciado, debe ser siem-

\footnotetext{
65 URÍAS (2014) p. 101.

66 Pauner (2014) p. 92

67 Muñoz-Torres (2002) p. 72.

68 En el mismo sentido, Véase De Fontcuberta (2011) p. 56.
} 
pre cuidadosa en el cumplimiento del deber de veracidad. Ello, a fin de que el ejercicio de la libertad de informar se encuentre amparado bajo el umbral normativo de protección que brinda la Constitución en el artículo 19 No 12. En este punto, compartimos con Bilbeny la importancia de recordar que el periodismo, de un modo u otro, colabora en forma activa en la construcción de la realidad ${ }^{69}$.

El deber de veracidad constituye uno de los principios básicos del periodismo y para llevarlo a la práctica -en casos como el de los juicios paralelos-, será necesario tomar algunas medidas; como por ejemplo, que la información sea verificada, clara, precisa, rigurosa, completa e imparcial, distinguiendo los hechos de las meras opiniones ${ }^{70}$. Asimismo, para dar cumplimiento a dicho requisito será fundamental poner atención a los usos periodísticos empleados por los medios de comunicación. De esta forma, los profesionales de la información debieran estar en condiciones de reflexionar sobre el significado y la forma que emplean para difundir hechos de interés público. En este sentido, en asuntos legales, el uso de la palabra "presunto" debiera estar necesariamente acompañado de la palabra "inocente" ${ }^{71}$. Esto, con el objeto de evitar confusiones y precipitadas interpretaciones de parte de quien recibe y/o accede a dicha información.

La información es una modalidad de poder que se encuentra presente en toda estructura social y ella guarda estrecha relación con los sistemas políticos y económicos ${ }^{72}$. Asimismo, es indiscutible que, al interior de un determinado estado, los medios de comunicación son protagonistas en el ejercicio de dicha forma de poder. Los medios de comunicación no son un universo aislado y autónomo ${ }^{73}$. Junto con las personas y asociaciones, son actores que ejercen las facultades propias de la libertad de información, con la finalidad última de alcanzar una opinión pública libre y deliberante.

Ya en el año 1988, Frank Bealey destacaba que "[s]in conocimiento, la democracia es un sistema defectuoso. Cuando se ignora alguna información, resultan obstaculizadas no solo la participación en la adopción de decisiones en el ámbito institucional, sino también la discusión popular y la controversia" 74 . De esta forma, para poder participar de la vida en su vertiente pública, es necesario acceder a la información, lo cual transforma dicha facultad en un elemento sustancial para toda democracia. Sin embargo, consideramos que no son intrascendentes las condiciones bajo las cuales una persona -o los medios de comunicación- obtienen la información que luego se difunde. Esto, por cuanto la información a la que se accede es apta para enjuiciar a nuestros representantes. Y, dentro de esta última faceta, cobra importancia la información de interés general o interés público.

Teniendo en cuenta todo lo anteriormente expuesto, no cabe duda de que la democracia conduce necesariamente a un gobierno visible y, con ello, controlable. Sin embargo, ante este panorama, es preciso destacar que la visibilidad impulsada por los medios, para

69 Bilbeny (2012) p. 80.

70 Bilbeny (2012) pp. 87 y 88.

71 BARATA (2009) p. 223.

72 SÁNCHEz (1996) p. 9.

73 SÁNCHEZ (1996) p. 10.

74 Bealey (1988) p. 263. 
cumplir su objeto fundamental, debe cumplir con los requisitos constitucionales exigidos para el correcto ejercicio del derecho. Por lo mismo, debe ser obtenida sin devaluar derechos y garantías procesales que -al igual que la libertad de informar- gozan de reconocimiento y amparo constitucional. Una interpretación contraria, sitúa a todas las personas, eventualmente, en una situación de indefensión frente a la opinión pública, pues se facultaría a los medios de comunicación a construir, bajo el umbral de protección de la libertad de información, una relación directa entre los hechos y los sujetos investigados, en etapas donde estos últimos ni siquiera han pasado a disposición de la justicia.

\section{A MODO DE CONCLUSIÓN: DESAFÍOS A FUTURO}

Las demandas informativas no pueden ni deben devaluar derechos fundamentales. La información debe ser respetuosa con los derechos de todas las personas, incluso los de aquellos que serán sometidos a un proceso judicial. Esto es un imperativo para todos, pero especialmente lo es para los medios de comunicación, en el momento en que ejercen la facultad de difundir hechos de interés público.

Toda sociedad que se dice democrática debe defender y cuidar el respeto de su derecho a la información. Dicho cumplimiento da cuenta de los principios democráticos a los que adhiere un Estado y de la defensa de los derechos y libertades que ese Estado efectúa. Sin embargo, como todo derecho, la libertad de información no es constitutiva de un derecho absoluto, sino que tiene restricciones. En el contexto nacional, la realidad nos demuestra que por medio del ejercicio de la libertad de informar sobre la ocurrencia de hechos -comprendiendo nombres e imágenes- es posible el surgimiento de un juicio paralelo que, más que a una valoración por parte de la opinión pública, se oriente al establecimiento de una presunción de sospecha y culpabilidad de las personas vinculadas al acaecimiento de esos hechos. Es esto último lo que ocasiona la devaluación de derechos fundamentales y garantías de tales personas y no la mera existencia de un juicio paralelo.

Los juicios paralelos no constituyen per se un inadecuado ejercicio de la libertad de información. Al contrario, contribuyen con frecuencia a la formación de una opinión publica libre, al debate ciudadano sobre temas de interés público y a una participación ciudadana informada, fortaleciendo, con ello, a la democracia. Únicamente tuercen el ejercicio de la libertad de informar cuando menoscaban el contenido esencial de otros derechos o garantías fundamentales y cuando incumplen el requisito de veracidad de la información y lo dispuesto en los Códigos de Ética de los medios.

En síntesis, el conflicto entre el ejercicio de la libertad de información y el ejercicio de otros derechos y garantías es evitable. Si se cumplen las premisas anteriormente enunciadas, la convicción a priori de la afectación de derechos mediante los juicios paralelos se convierte en la excepción -no amparada por el ordenamiento jurídico- y no en la regla general, como comúnmente se considera. 


\section{BIBLIOGRAFÍA CITADA}

Aguiar de Luque, Luis (1993): "Los límites de los derechos fundamentales", Revista del Centro de Estudios Constitucionales, vol. 14: pp. 9-34.

Aliste Santos, Tomás (2018): "Poder judicial, justicia penal y medios de comunicación en un contexto comunicativo de posverdad”, en Rodríguez-García, Nicolás; Carrizo, Adán y Leturia, Francisco (dirs.) Justicia penal pública y medios de comunicación (Valencia, Tirant lo Blanch) pp. 41-58.

BARATA, Francesc (2009): "La devaluación de la presunción de inocencia en el periodismo", Análisis, vol. 39: pp. 217-236.

Bealey, Frank (1988): Democracy in the Contemporary State (Oxford, Clarendon Press).

BecCaria, Cesare (2015): Tratado de los delitos y de las penas (Madrid, Universidad Carlos III de Madrid).

Bilbeny, Norbert (2012): Ética del periodismo (Madrid, Ediciones de la Universidad de Barcelona).

Bordalí Salamanca, Andrés (2013): "La independencia de los jueces en la aplicación de la ley dentro de la organización judicial”, Revista Chilena de Derecho, vol. 40, No 2: pp. 609-634.

Bordalí Salamanca, Andrés; Cortez Matcovich, Gonzalo y Palomo Vélez, Diego (2013): Proceso civil. El juicio ordinario civil de mayor cuantía (Santiago, Abeledo PerrotThomson Reuters, primera edición).

Bordalí Salamanca, Andrés (2009): "El derecho fundamental a un tribunal independiente e imparcial en el ordenamiento jurídico chileno", Revista de Derecho de la Pontificia Universidad Católica de Valparaiso, vol. 33: pp. 263-302.

Calamandrei, Piero (1960): Proceso y democracia (Trad. Héctor Fix Zamudio, Buenos Aires, Ediciones Jurídicas Europa-América).

Carbonell, Miguel (2009): Transparencia, ética pública y combate a la corrupción. Una mirada constitucional (Ciudad de México, Universidad Nacional Autónoma de México).

Cea Egaña, José Luis (2012): Derecho constitucional chileno, Tomo II (Santiago de Chile, Ediciones Universidad Católica de Chile).

Cea Egaña, José Luis (2013): Derecho constitucional chileno, Tomo III (Santiago de Chile, Ediciones Universidad Católica de Chile).

Couture, Eduardo (2010): Fundamentos del Derecho Procesal Civil, Tomo I (Santiago de Chile, Punto Lex-Thomson Reuters).

De Fontcuberta, Mar (2011): La noticia. Pistas para percibir el mundo (Barcelona, Editorial Paidós).

Díaz, Maureen y Mellado, Claudia (2017): "Agenda y uso de fuentes en los titulares y noticias centrales de los medios informativos chilenos. Un estudio de la prensa impresa, online, radio y televisión”, Cuadernos.info, vol. 40: pp. 107-121.

Fuentes Orellana, María Fernanda (2011): "El derecho a la honra como límite a la libertad de información hasta el momento de la acusación penal", Revista de Derecho de la Pontificia Universidad Católica de Valparaíso, vol. 37: pp. 547-564. 
Harbottle Quirós, Frank (2017): "Independencia Judicial y Juicios Penales Paralelos", ACADEMO, Revista de Investigación en Ciencias Sociales y Humanidades, Julio 2017, vol. 4, No 1. Disponible en: https://dialnet.unirioja.es/servlet/ articulo?codigo=6069620. Fecha de consulta: 10 de diciembre de 2018.

Huertas Martín, Isabel (2018): "Proceso penal y comunicación en el siglo XXI: el inevitable juicio paralelo, el prescindible juicio paralelo show”, en RodríGUEZ-García, Nicolás; Carrizo, Adán y Leturia, Francisco (dirs.) Justicia penal pública y medios de comunicación (Valencia, Tirant lo Blanch) pp. 405-455.

Iglesias BÁreZ, Mercedes (2011): Estructura orgánica y derechos fundamentales en la Constitución española de 1978 (Salamanca, Ediciones Universidad de Salamanca).

JuAnes Peces, Ángel (2007): "Los juicios paralelos. El derecho a un proceso justo. Doctrina jurisprudencial en relación con esta materia. Conclusiones y juicio crítico en relación con las cuestiones analizadas", en Fresneda Plaza, Felipe (dir.), Justicia y Medios de Comunicación (Madrid, Consejo General del Poder Judicial) pp. 61-92.

Leturia Infante, Francisco (2017): "La problemática de los juicios paralelos en la jurisprudencia y doctrina española", Revista Ius et Praxis, vol. 23, No 2: pp 21-50.

Leturia Infante, Francisco (2018): “Tensiones y conflictos entre la administración de justicia y los medios de comunicación”, en Rodríguez-García, Nicolás; Carrizo, Adán y LetUria, Francisco (dirs.) Justicia penal pública y medios de comunicación (Valencia, Tirant lo Blanch) pp. 25-40.

Maturana Miquel, Cristián y Montero López, Raúl (2012): Derecho Procesal Penal, Tomo I (Santiago, Abeledo Perrot-Thomson Reuters, segunda edición actualizada y complementada).

Maturana Miquel, Cristián y Montero López, Raúl (2012): Derecho Procesal Penal, Tomo II (Santiago, Abeledo Perrot-Thomson Reuters, segunda edición actualizada y complementada).

Muñoz Sabaté, Lluis (2001): Fundamentos de prueba judicial civil. L.E.C. (Ley de enjuiciamiento civil) 1-2000 (Barcelona, J. M. Bosch Editor).

Muñoz-Torres, Juan Ramón (2002): Por qué interesan las noticias. Un estudio de los fundamentos del interés informativo (Barcelona, Editorial Herder).

Nogueira Alcalá, Humberto (2003): "La constitucionalización del proceso: el acceso a la jurisdicción, tutela efectiva o debido proceso", en FERrada, Juan Carlos (coord.), La constitucionalización del derecho chileno (Santiago, Universidad Austral de Chile).

Nogueira Alcalá, Humberto (2005a): "Consideraciones sobre el derecho fundamental a la presunción de inocencia”, Ius et Praxis, vol. 11, No 1: pp. 221-241.

Nogueira Alcalá, Humberto (2005b): “Aspectos de una Teoría de los Derechos Fundamentales: La Delimitación, Regulación, Garantías y Limitaciones de los Derechos Fundamentales", Ius et Praxis, vol. 11, No 2: pp. 15-64.

Nogueira Alcalá, Humberto (2012): El debido proceso en la Constitución y el sistema interamericano (Santiago, Librotecnia, segunda edición).

Orsi, Omar (2018): "Justicia y delito en los medios de comunicación”, en RodríGuezGarcía, Nicolás; Carrizo, Adán y Leturia, Francisco (dirs.) (Valencia, Tirant lo Blanch) pp. 59-100. 
Ortega Gutiérrez, David (2017): El derecho a la comunicación. Un análisis jurídico-periodistico (Madrid, Editorial Universitaria Ramón Areces).

Ovejero Puente, Ana María (2017): "Protección del derecho a la presunción de inocencia”, UNED, Revista Teoría y Realidad Constitucional, No 40: pp. 431-455.

Pauner Chulvi, Cristina (2014): Derecho de la información (Valencia, Tirant lo Blanch).

Ruiz-Rico Ruiz, Gerardo y Carazo Liébana, María José (2013): El derecho a la tutela judicial efectiva. Análisis jurisprudencial (Valencia, Tirant lo Blanch).

SÁnchez GonzÁlez, Santiago (1996): Los medios de comunicación y los sistemas democráticos. (Madrid, Marcial Pons).

San Miguel Caso, Cristina (2018): "La cobertura mediática en el sistema de la estrategia de la defensa penal”, en Rodríguez-García, Nicolás; Carrizo, Adán y Leturia, Francisco (dirs.) Justicia penal pública y medios de comunicación (Valencia, Tirant lo Blanch) pp. 359-377.

URÍAs, Joaquín (2014): Principios de Derechos de la Información (Madrid, Tecnos).

\section{NORMAS CITADAS}

Código Orgánico de Tribunales.

Código Procesal Penal.

Consejo de Ética Medios de Comunicación. Resolución No 220, 25 de julio de 2018.

Convención americana de Derechos Humanos (Pacto de San José) (22/11/1969).

Convenio Europeo para la protección de los derechos humanos y de las libertades FUNDAMENTALES $(4 / 11 / 1950)$.

Declaración de los Derechos del Hombre y del Ciudadano. Aprobada por la Asamblea Nacional Constituyente francesa el 26 de agosto de 1789.

Declaración Universal de Derechos Humanos. Adoptado por la Asamblea General de las Naciones Unidas en su Resolución 217 A (III), el 10 de diciembre de 1948.

LEY No 19.620 (5/08/1999), Dicta normas sobre adopción de menores.

LEY No 19.733 (4/06/2001), Sobre libertades de opinión e información y ejercicio del periodismo.

LEY No 19.947 (17/5/2004), Nueva ley de matrimonio civil.

Pacto Internacional de Derecho Civiles y Políticos. Adoptado y abierto a la firma, ratificación y adhesión por la Asamblea General en su resolución 2200 A (XXI), de 16 de diciembre de 1966.

\section{JURISPRUDENCIA CITADA}

Affatre Kyprianou vs. Chypre. Tribunal Europeo de Derechos Humanos. Sentencia de 15 de diciembre de 2005.

Berns y EWERT vs. LuXemburgo. Comisión Europea de Derechos Humanos. Decisión del 6 de marzo de 1991.

Claude Reyes y otros vs. Chile. Corte Interamericana de Derechos Humanos. Sentencia del 19 de septiembre de 2006. Serie C No 151. 
Corte IDH. La Colegiación Obligatoria de Periodistas. Opinión Consultiva OC-5/85 del 13 de noviembre de 1985.

Daktaras vs. Lituania. Tribunal Europeo de Derechos Humanos. Sentencia de 10 de octubre de 2000.

De Allenet de Ribemont vs. Francia. Tribunal Europeo de Derechos Humanos. Sentencia de 10 de febrero de 1995.

Fontevecchia y D'amico vs. ARgentina. Corte Interamericana de Derechos Humanos. Sentencia del 29 de noviembre de 2011. Serie C No 238.

Gómez de Liaño y Botella vs. España. Tribunal Europeo de Derechos Humanos. Sentencia de 22 de julio de 2008.

Herrera Ulloa vs. Costa Rica. Corte Interamericana de Derechos Humanos. Sentencia del 2 de julio de 2004. Serie C No 107.

Jerusalem vs. Austria. Tribunal Europeo de Derechos Humanos. Sentencia del 27 de mayo de 2001.

Kimel vs. Argentina. Corte Interamericana de Derechos Humanos. Sentencia de 2 de mayo de 2008. Serie C No 177.

KRAUSE vs. SuIza. Comisión Europea de Derechos Humanos. Decisión del 3 de octubre de 1978.

LigENS VS. Austria. Tribunal Europeo de Derechos Humanos. Sentencia del 8 de julio de 1986.

López LONE Y OtRos vs. HonduRAs. Corte Interamericana de Derechos Humanos. Sentencia del 5 de octubre de 2015. Serie C No 141.

Otegi Mondragón vs. España. Tribunal Europeo de Derechos Humanos. Sentencia del 6 de noviembre de 2008.

Palamara Iribarne vs Chile. Corte Interamericana de Derechos Humanos. Sentencia del 22 de noviembre de 2005. Serie C No 135.

PIERSACK Vs. BÉLGICA. Tribunal Europeo de Derechos Humanos. Sentencia del 1 de octubre de 1982.

Sunday Times vs. ReIno Unido. Tribunal Europeo de Derechos Humanos. Sentencia de 26 de abril de 1979.

STC 190/1996.

STC 214/1991.

STC 28/1996.

STC 29/2009.

STC $107 / 1988$.

STC $134 / 1999$.

STC 6/1988.

Thorgeir Thorgeirson vs. IsLAndia. Tribunal Europeo de Derechos Humanos. Sentencia del 25 de junio de 1992.

Tristán Donoso vs. Panamá. Corte Interamericana de Derechos Humanos. Sentencia del 27 de enero de 2009. Serie C No 193. 


\section{PUBLICACIONES PERIODÍSTICAS EN SITIOS ELECTRÓNICOS}

"25 años del crimen de Alcàsser”, www.elpais.com (13/11/2017). Disponible en: https:// elpais.com/elpais/2017/11/12/album/1510500183_634784.html. Fecha de consulta: 7 de mayo de 2019.

"Colegio médico expulsa a doctora Cordero", www.emol.com (12/6/2004). Disponible en: https:/www.emol.com/noticias/nacional/2004/06/11/150060/colegio-medico-expulsaa-doctora-cordero.html. Fecha de consulta: 7 de mayo de 2019.

“Doctora Cordero no se 'averguenza", www.lanacion.cl (13/8/2003). Disponible en: http://lanacion.cl/2003/08/13/doctora-cordero-no-se-averguenza/. Fecha de consulta: 7 de mayo de 2019.

"Dolores Vázquez, un caso que sigue abierto 15 años después”, www.elmundo.es (13/10/2014). Disponible en: https://www.elmundo.es/andalucia/2014/10/13/543bb3f 0ca4741a3338b4580.html. Fecha de consulta: 7 de mayo de 2019.

"El triste prontuario de la doctora Cordero", www.radiozero.cl (8/7/2017). Disponible en: https:/www.emol.com/noticias/nacional/2004/06/11/150060/colegio-medico-expulsaa-doctora-cordero.html. Fecha de consulta: 7 de mayo de 2019.

"Familiares de Sergio Landskron descartan su vínculo con 'grupo terrorista' y aseguran que fue víctima de bombazo", www.elmostrador.cl (25/9/2014). Disponible en: https://m. elmostrador.cl/noticias/pais/2014/09/25/familiares-de-sergio-landskron-descartan-queestuviera-vinculado-a-grupo-terrorista-y-aseguran-que-fue-victima-de-bombazo/. Fecha de consulta: 7 de mayo de 2019.

"La Audiencia rechaza indemnizar con cuatro millones a Dolores Vázquez", www.elpais. com (23/10/2012). Disponible en: https://elpais.com/sociedad/2012/10/23/actualidad/1350994173_584629.html. Fecha de consulta: 7 de mayo de 2019.

"Los pasos del caos en el caso Catrillanca", www.pautapunto.cl (20/12/2018). Disponible en: https:/www.pauta.cl/politica/paso-a-paso-del-caso-en-el-homicidio-camilo-catrillanca. Fecha de consulta: 7 de mayo de 2019.

“Menor del caso Catrillanca 'Querí que te mate como a tu peñi', me dijeron”. www.lanacion. cl (11/03/2019). Disponible en: http://lanacion.cl/2019/03/11/menor-del-caso-catrillancaqueri-que-te-mate-como-a-tu-peni-me-dijeron/. Fecha de consulta: 7 de mayo de 2019.

"Nabila Rifo demandó a Canal 13, a Tonka Tomicic y al ex director de 'Bienvenidos", www.cooperativa.cl (28/12/2017). Disponible en: https:/www.cooperativa.cl/noticias/ entretencion/television/canal-13/nabila-rifo-demando-a-canal-13-a-tonka-tomicic-y-alex-director-de/2017-12-28/163358.html. Fecha de consulta: 7 de mayo de 2019.

"Nabila Rifo llega a acuerdo extrajudicial con Canal 13 tras divulgación de su ficha ginecológica”, www.elmostrador.cl (8/6/2018). Disponible en: https://m.elmostrador.cl/ $\mathrm{dia} / 2018 / 06 / 08 /$ nabila-rifo-llega-a-acuerdo-extrajudicial-con-canal-13-tras-divulgacionde-su-ficha-ginecologica/. Fecha de consulta: 7 de mayo de 2019.

“Temor en el centro de Santiago Chile: manipulaba una bomba casera, le estalló en la cara y murió en el acto", www.elclarin.com (26/9/2014). Disponible en: https://www.clarin. com/mundo/Chile-manipulaba-casera-estallo-murio_0_S1HSZSt9DQl.html. Fecha de consulta: 7 de mayo de 2019. 
Droguett Gonzalez, Carmen / Walker Silva, Nathalie — "El derecho a ser informado sobre los asuntos de interés público ..."

"Video: Captan momento en que hombre se quema tras explotar artefacto en Barrio Yungay", www.puranoticia.cl (25/9/2014). Disponible en: https://www.puranoticia.cl/front/ contenido/2014/09/25/113850/video-captan-momento-en-que-hombre-se-quema-trasexplotar-artefacto-en-barrio-yungay.php. Fecha de consulta: 7 de mayo de 2019. 